NBER WORKING PAPER SERIES

\title{
PHYSICIAN PAYMENTS AND INFANT \\ MORTALITY: EVIDENCE FROM \\ MEDICAID FEE POLICY
}

\author{
Janet Currie \\ Jonathan Gruber \\ Michael Fischer
}

Working Paper No. 4930

\section{NATIONAL BUREAU OF ECONOMIC RESEARCH \\ 1050 Massachusetts Avenue \\ Cambridge, MA 02138 \\ November 1994}

This paper is part of NBER's research programs in Health Care and Public Economics. Any opinions expressed are those of the authors and not those of the National Bureau of Economic Research.

(c) 1994 by Janet Currie, Jonathan Gruber and Michael Fischer. All rights reserved. Short sections of text, not to exceed two paragraphs, may be quoted without explicit permission provided that full credit, including (C) notice, is given to the source. 


\title{
PHYSICIAN PAYMENTS AND INFANT \\ MORTALITY: EVIDENCE FROM \\ MEDICAID FEE POLICY
}

\begin{abstract}
While efforts to improve the health of the uninsured have focused on demand side policies such as increasing insurance coverage, supply side changes may be equally important. Yet there is little direct evidence on the effect of policies designed to increase the supply of Medicaid services to the poor. We provide such evidence by examining the relationship between infant mortality and the ratio of Medicaid fees to private fees for obstetrician/gynecologists. We build a state and year specific index of the fee ratio for 1979-1992, a period of substantial variation in relative Medicaid fees. We find that increases in fee ratios are associated with significant declines in the infant mortality rate. We also find that higher fees raise payments made to physicians and clinics under the Medicaid program, but reduce payments to hospitals. Finally, we compare the cost effectiveness of reducing infant mortality by increasing fee ratios to the efficacy of reducing mortality by expanding the Medicaid eligibility of pregnant women. Although our results are sensitive to the time period used, we conclude that raising fee ratios is at least as cost effective as increasing eligibility.

\section{Janet Currie}

Department of Economics

UCLA

405 Hilgard Avenue

Los Angeles, CA 90024

and NBER

Michael Fischer

Yale Medical School

Yale University

New Haven, CT 06520

Jonathan Gruber

Department of Economics, E52-274c

MIT

50 Memorial Drive

Cambridge, MA 02139

and NBER
\end{abstract}


At 10 infant deaths per 1000 births, the U.S. ranks below 20 other industrialized nations in terms of the infant mortality rate (U.S. House of Representatives, 1992). Congress has responded to this situation by dramatically increasing the number of pregnant women eligible for health insurance coverage under the Medicaid program. As a result, the number of women 15 to 44 years old who were eligible for Medicaid coverage in the event of pregnancy grew by $140 \%$ between 1979 and 1990 (Currie and Gruber, 1994).

However, even if these changes were effective in increasing the demand for prenatal, obstetrical, and neonatal care among the poor, they do not in themselves guarantee access to medical care. Many observers have alleged that there is a shortfall in the supply of physicians, and especially of obstetrician/gynecologists (ob/gyns), willing to serve Medicaid patients. Mitchell and Schurman (1984) report that in 1977 and 1978, 23.5\% of primary care physicians, and 35.6\% of obstetricians, saw no Medicaid patients. And in a recent survey by the Physician Payment Review Commission, 43 state Medicaid directors identified low physician participation rates as a problem (PPRC, 1991). These figures suggest that the increased demand for services generated by expansions of the Medicaid program could go unmet.'

An alternative approach to improving birth outcomes is to focus on the supply side of the market. One natural supply side $100 \mathrm{l}$ is Medicaid fee policy. The low fees paid by state Medicaid programs represent a major potential deterrent to physician willingness to see Medicaid patients. Holahan (1991) reports that the ratio of Medicaid fees to private fees was approximately 0.5 for most procedures surveyed, and 0.56 for total obstetrical care with vaginal delivery. And in the PPRC survey cited above, 38 states identified low fees as the major cause of low physician participation

\footnotetext{
${ }^{1}$ It is even possible that increases in demand for services among the near-poor could "crowd out" (potentially) needier poorer women. In this case, increasing eligibility could worsen birth outcomes.
} 
rates. A large body of research suggests that increasing the ratio of Medicaid fees relative to private sector fees will increase physician participation in the Medicaid program (Hadley, 1979; Sloan, Mitchell, and Cromwell, 1978; Held and Holahan, 1985; Mitchell, 1991). Furthermore, Mitchell and Schurman (1984) and Adams (1992) find that the participation of ob/gyns is especially responsive to fee increases.

But increasing the number of physicians willing to serve Medicaid patients will not necessarily lead to improvements in infant mortality, for two reasons. First, many poor women and children already receive care from clinics and emergency rooms. ${ }^{2}$ Decker (1993) and Long et al. (1985) find that increased Medicaid fees caused patients to shift from other sources of care to physician's offices but did not increase the number of ambulatory visits they received. This kind of change will have no effect on health outcomes unless the quality of care is significantly higher in physician's offices.

Second, Fossett and Peterson (1989) and Fossett et al. (1992) argue that fee policy is likely to have small effects due to the segregation of the poor into areas that are underserved by physicians. For example, Fossett et al. (1992) compared Chicago neighborhoods with $50 \%$ of the population on welfare to neighborhoods with $10 \%$ of the population on welfare and found that there were twice as many physicians practicing in the wealthier areas (on a per child basis). They conclude that fee increases will not increase the supply of physician services available to poor families unless they are large enough to induce physicians to move into underserved markets. Thus, the sensitivity of physician participation to fee policy uncovered by the earlier literature does not prove that fee policy can be effective in improving health outcomes.

${ }^{2}$ For example, Aday and Anderson (1984) report that relative to those with private insurance, Medicaid enrollees were $33 \%$ less likely to have a regular physician and 2.4 times more likely to have a source of regular care other than a physician's office. 
In this paper we move beyond the earlier physician participation literature by directly examining the effect of physician fees on a particular health outcome: infant mortality. ${ }^{3}$ Using statelevel data we model infant mortality over the 1980-1992 period as a function of the ratio of Medicaid ob/gyn fees to private sector fees. Our estimates exploit the substantial variation in this fee ratio across states and over time. We also examine the relationship between the fee ratio and Medicaid expenditures, in order to determine whether changes in Medicaid fees are a cost effective way to reduce infant mortality. Finally, we use the measure of Medicaid eligibility developed in Currie and Gruber (1994) to contrast the cost efficiency of reducing infant mortality by changing demand-side or supply-side policies.

We find that increases in the Medicaid fee ratio are associated with small, but significant, declines in the infant mortality rate. Our central estimates suggest that raising the fee ratio by 10 percentage points lowers infant mortality by $0.5-0.9 \%$. This result is robust to variation in the sample period and to the measure of the fee ratio. We also find that higher fees raise payments to physicians and clinics under the Medicaid program, but that these increases appear to be fully offset by reduced payments to hospitals, so that lowering infant mortality through fee policy appears to be a "free lunch". The finding for hospital costs, however, is fairly sensitive to the specification chosen. As in Currie and Gruber (1994), we find that expansions of Medicaid eligibility also reduce infant mortality, but that they increase payments to both physicians and hospitals. Hence, our results suggest that raising Medicaid fees may be more cost effective, and certainly no less cost effective, than expanding eligibility as a means of reducing infant mortality.

\footnotetext{
${ }^{3}$ We are aware of no other study which has examined the effect of fee policy on health outcomes. There is a sizeable literature which assess the effects of provider supply, and in particular clinic supply, on birth outcomes; see Grossman and Jacobitz (1981) and Frank (1991) for examples. But this literature does not speak to the effects of changing physician reimbursement, especially if there is important site shitting between clinics and doctors' offices.
} 
The rest of the paper is laid out as follows. In Part I we discuss the ways in which access to medical care might be effective in reducing infant mortality. In Part II, we describe our methodology and data sources with special attention to the construction of our measure of the fee ratio. Part III presents our estimates, and Part IV concludes with a discussion of the policy implications of our findings.

\section{Part I: The Role of the Physician in Improving Infant Outcomes}

Decreases in the infant mortality rate can occur through one of two channels: improvements in the underlying health of the fetus, and increases in the intensity or efficacy of interventions undertaken to keep fetuses of a given health alive. The latter channel can be quite expensive. Schwartx (1989) reports that although babies weighing less than 2500 grams account for only $9 \%$ of neonatal hospital caseloads, they account for $57 \%$ of the cost of neonatal hospital care. The average cost of caring for a surviving low birthweight baby was $\$ 9,712$ compared to $\$ 678$ for an infant weighing more than 2,500 grams. These costs rise as birthweight falls; in 1984, the cost of saving an infant with birthweight below 1000 grams was $\$ 118,000$ (U.S. Office of Technology Assessment, 1987).

These high costs have led policy makers to promote prenatal care as a means of reducing the infant mortality rate through improved fetal health. Clinical studies indicate that prenatal care is a cost effective way to achieve reduced mortality. The majority of unhealthy infants are pre-term. Inexpensive screenings can identify women at risk of pre-term deliveries due to medical, social, or economic factors. Given early identification of high-risk pregnancies, many pre-term births could be prevented, either through appropriate counseling (about diet and about dangers to the fetus from cigarettes, drugs or alcohol consumption), or drug therapies. Several studies cited in the Institute 
of Medicine's influential 1985 report suggest that providing appropriate prenatal care to high-risk women could significantly improve infant health.

Medicaid policy can affect infant mortality rates through either of these two channels: by improving the utilization of prenatal care and thereby infant health, or by increasing access to the expensive interventions necessary to keep unhealthy infants alive. Even if the two aspects of Medicaid policy considered in this paper, increasing Medicaid eligibility and raising Medicaid fees, are effective in lowering infant mortality, they may take different routes to this goal.

Expanding Medicaid eligibility is likely to increase the number of woman and newborns receiving expensive hospital services. Hospitals that participate in Medicare are prohibited from refusing to treat, or from transferring, any woman already in labor (Office of Technology Assessment, 1987). Furthermore, uncompensated costs due to childbirth account for $17.4 \%$ of hospital's uncompensated care costs, by far the largest single component (Saywell et al., 1989). It is not surprising then that hospitals make every effort to enroll eligible pregnant women in Medicaid (Gold et al., 1993). Once enrolled, women and their newborns may receive more expensive services than they would have otherwise -- Hadley et al. (1991) and Wenneker et al. (1990) report that uninsured patients receive less intensive hospital treatments than insured patients along several margins. Haas et al. (1993) found that increases in Medicaid eligibility in Massachusetts led to increases in the use of cesarean delivery.

On the other hand, physicians are not required to participate in Medicaid, and expanding Medicaid eligibility will do little to increase a physician's incentive to participate. Hence, it would not be surprising to find that increasing Medicaid eligibility had little effect on the probability that a woman received prenatal care. Evidence from case studies of the Medicaid expansions of the $1980 \mathrm{~s}$ is mixed on this point. Piper et al. (1990) found that a 1985 expansion of Medicaid eligibility 
to married woman in Tennessee increased enrollments, but that most of the increase took place within the thirty days prior to delivery, so there was no effect on the use of prenatal care. Currie and Gruber (1994), however, found strong evidence that eligibility expansions lowered infant mortality, but only mixed evidence regarding effects on the utilization of prenatal care.

In contrast, increasing fee ratios does provide physicians with an incentive to provide prenatal care services. The literature cited above shows that higher fees increase the access of the Medicaid population to doctor's offices. If there is excess demand among pregnant women for prenatal care, and prenatal care is effective in improving fetal health, then increasing fee ratios may be a more costeffective way to decrease infant mortality than increasing eligibility.

There are at least two reasons, however, to believe that fee policy will not be as cost effective as this discussion suggests. First, as noted above, if higher fees simply lead to a shifting in the site of prenatal care delivery, or if poor areas continue to be underserved, fee policy will not improve access to care. Furthermore, unless there is excess demand for physician services among high risk women, increasing supply will have little effect. If a high risk woman does not seek care from physicians, or perhaps does not even know that she is pregnant during the first trimester, then neither increased eligibility nor higher physician fees will improve birth outcomes unless accompanied by more intensive outreach programs to high risk populations.

Second, in contrast to clinical studies, the economics literature suggests that the effects of prenatal care are small. As a number of economists have noted, studies based on differences in outcomes among women who do and do not receive prenatal care are likely to be biased by selection; see Harris (1982) for a discussion. Compared to clinical studies, studies based on survey data that attempt to control for selection bias typically find much smaller effects of prenatal care (Rosenzweig 
and Schultz, 1982, 1983, 1988; Frank et al., 1991; Corman et al.; Grossman and Joyce, 1990). If prenatal care has only a small effect compared to hospital interventions, than the cost per infant life saved may be similar despite the large "per case" cost of interventions. Thus, the relative efficacy of these two types of policies is ultimately an empirical question.

\section{Part II: Methodology and Data}

a) Methodology

In order see whether raising the ratio of Medicaid fees relative to private fees reduces infant mortality, we estimate models of the form:

$$
\mathrm{IM}_{\mathrm{k}}=\alpha+\beta_{1} \operatorname{RELFEE}_{j-1}+\mathrm{STATE}_{j} \delta_{1}+{\operatorname{YEAR}, \delta_{2}}_{2}+\epsilon_{\mathrm{j}}
$$

where $\mathrm{j}$ indexes states and $\mathrm{t}$ indexes years,

IM is the infant mortality rate,

RELFEE is the Medicaid fee relative to the private sector fee,

STATE is a vector of state fixed effects,

YEAR is a vector of year fixed effects.

The lagged Medicaid fee is used in order to allow for lags in the reaction of physicians to fee changes, and because if fee changes operate by encouraging the use of prenatal care, they will affect infant mortality rates with a lag. The year effects control for secular time trends in the infant mortality rate and in fee ratios. State effects control for any fixed state characteristics that might be correlated with both fees and outcomes. ${ }^{5}$ Thus, in this model the effect of Medicaid fee policy is

the difference may reflect the fact that clinical studies focus on the gains that could be attained by high risk women under ideal circumstances, whereas surveys reflect the impact of prenatal care as it is practiced in the field.

s For example, Gold et al. (1993) report that states with high proportions of low birthweight births and high fractions of women who delayed obtaining prenatal care, were more likely to extend Medicaid coverage to previously ineligible groups of pregnant women and to set up complementary advertising and outreach programs. 
identified by changes in fee ratios within states and over time.

There have also been substantial increases in eligibility for the Medicaid program over the 1980s, as documented by Currie and Gruber (1994). If states that increased fees also increased eligibility, and if increased eligibility improved infant outcomes, then models that ignore eligibility policy could overstate the effect of fee policy on infant mortality. Thus, we also estimate models of the form:

(2) $\quad \mathrm{IM}_{\mathrm{j}}=\alpha+\beta_{1}$ RELFEE $_{j-t}+\beta_{2} \mathrm{ELIG}_{\mathrm{j}}+\operatorname{STATE}_{j} \delta_{1}+\mathrm{YEAR}_{\delta_{2}}+\epsilon_{\mathrm{j}}$

where $\mathrm{ELIG}_{\mathrm{j}}$ is the fraction of the 15 to 44 year old female population who would be eligible for Medicaid coverage of a pregnancy in each state and year. ${ }^{6}$ In what follows, we will use these estimates to compare the cost effectiveness of demand-side and supply-side changes in Medicaid policies.

\section{b) Dependent Variable}

The infant mortality rate is the percentage of infants who die within the first year of life. Data for the full sample of births in each state and year comes from the Vizal Statistics. For 1979 to 1988 , we use the final data reports, while for 1989 to 1992 we use preliminary statistics.

We also estimate models of the forms (1) and (2) using measures of Medicaid expenditures as the dependent variable. States report payments made under the Medicaid program to the Health Care Financing Administration each year. ${ }^{7}$ These reports break expenditures down by class of

'This measure captures Medicaid eligibility at the start of the year, in order the capture both effects on prenatal care and point-of-birth interventions during that year.

${ }^{7}$ We are grateful to Killard Adamache of Health Services Research, Inc. for providing us with these data. 
provider, and by recipient category. Unfortunately, the expenditure data are not available by type of service (i.e. childbirth) or by detailed population category (i.e. pregnant women and infants). We focus on expenditures on physicians, clinics, and inpatient and outpatient hospital costs for all nondisabled children and non-disabled/non-elderly adults. Expenditures for each state are normalized so that they are per woman 15 to 44 years old. All figures are in \$100s of 1986 doliars. Expendiures for hospital inpatient and outpatient services are deflated using the Consumer Price Index for hospital services, while expenditures for physician and clinic services are deflated using the CPI for physician's services.

\section{c) Fee Ratio}

Our key regressor is the ratio of Medicaid to private fees for ob/gyns. There is no annual state-level data available on relative Medicaid fees. We therefore construct a fee index for each state over time in three steps. First, the numerator of the fee ratio is constructed from data on Medicaid fees for ob/gyns by state and year. Data on Medicaid fees is taken from a number of sources. When it is availabie, we use the fees paid to specialists for CPT code 59400, total obstetrical care (including prenatal care, delivery, and postnatal care) for vaginal delivery. For some states, only the delivery fee and the fee per prenatal visit is reported. In these cases we follow the Alan Guttmacher Institute (AGI, 1987) in assuming that the average pregnant woman receives 8.7 prenatal visits and one postnatal visit, and use these figures to estimate the appropriate total ("global") fee.

We constructed our Medicaid state/year fee series from the following government and private sources, each of which collected data from each state on their payment policies at a point in time: Holahan (1982) for 1979; Health Care Financing Administration (1982, 1983, 1984, 1986); Gold and Kenney (1985); AGI (1987); American College of Obstetricians and Gynecologists (1988, 1990); 
Physician Payments Review Commission (1989); Holahan (1991) for 1990; and Gold et al. (1993) for 1991 and 1992.

There are some differences in the numbers reported by these sources. For example, Holahan (1982) only reports the average fee for the ob/gyn specialty, rather than for the specific cost of prenatal care and delivery. Holahan (1991) does not report the fee for prenatal care visits in some cases; for these states, the visit fee is imputed from the fee for a basic office visit in the state. In a number of states, some years of data are missing, and data is missing for all states in 1980 and 1981. Where data is available before and after a gap, we bridge the gap assuming a constant growth rate in fees during the period; where the endpoints are not available, we drop the state from our sample. As a result, we do not use data from Alaska, Kentucky, Texas, and Wyoming. We are also missing data from Rhode Island, which did not report its Medicaid expenditures to the Health Care Financing Administration.

We do not have data for private fees by state and year. Hence, in order to construct the denominator of our series, we start with the private fee for vaginal delivery in each state in 1989, which was collected in a survey by PPRC and reported in Schwartz et al. (1991). We then use statespecific information on annual hospital cost inflation to deflate this figure backwards and inflate it forward in order to derive a figure for each state and year. ${ }^{4}$ Unfortunately, no state-specific annual data on physician cost inflation is available. Nationally, hospital costs rose $310 \%$ between 1979 and 1992 , as compared to a $250 \%$ increase for physician costs. Ob/gyn costs, however, may have grown at a more rapid rate than those of other physicians due to the explosion in malpractice insurance costs

${ }^{4}$ Data on hospital cost inflation are from American Hospital Association (AHA, various years). We use the change in total hospital expenses per adjusted patient day, which is a weighted average of inpatient days and outpatient visits, where the relative revenue contribution of each is used as weights. 
for this specialty over the $80 \mathrm{~s} .{ }^{5}$ Hence, hospital cost growth may be a reasonable proxy for growth in ob/gyn costs.

Dividing the Medicaid fee in each state and year by the estimated private fee in that state and year yields our estimate of the fee ratio. However, the Schwartz et al. (1991) private fee data exclude reimbursement for pre/postnatal care and the Medicaid fee is a global figure, so this ratio is likely to be an overestimate of the true fee ratio. We therefore adjust our calculated fee ratio for each state and year using a point in time estimate of the true fee ratio in each state, as reported in two different sources. First, Schwartz et al. report (for 1989) the ratio of Medicaid fees for vaginal delivery to private fees for vaginal delivery. Second Holahan (1991) reports (for 1990) the ratio of average Medicaid reimbursements to private reimbursements for a basket of ob/gyn services (including services other than childbirth). Using each of these fee ratios for each state at a point in time, we create two versions of our Fee Ratio variable as follows:

Fee Ratio A = Fee Ratio (山ll yoars) $*$ [Schwartz Fee Ratio/Fee Ratio ${ }_{\text {1989] }}$

Fee Ratio B = Fee Ratio ${ }_{(\text {wl year) }}$ * [Holahan Fee Ratio/Fee Ratio $\left.{ }_{1990}\right]$.

Neither adjustment factor is ideal for our purposes; the Schwartz ratio excludes non-delivery services, and the Holahan ratio does not focus only on global delivery fees. By using both we hope to check the sensitivity of our results to changes in our underlying assumptions. ${ }^{6}$

The result of these calculations are shown in Figure 1 and in Table 1 . Figure 1 graphs the

\footnotetext{
'Unfortunately, the detailed Consumer Price Index for obstetricians' services was discontinued in 1978.

'Note that this procedure is equivalent to taking the point in time estimate of the fee ratio from HLAA and Holahan, and deflating it through time by the state-specific ratio of the Medicaid fee to hospital costs.
} 
average nationwide Fee Ratio A, by year, from 1979 to $1992 .^{7}$ The figure shows that there is considerable temporal variation in the fee ratio. Between 1979 and 1982 , the fee ratio was relatively constant. It then fell sharply until 1985 . Between 1986 and 1988, Medicaid fees rose rapidly relative to private fees, and they continued this relative rise at a slower pace for the remainder of our sample period."

Table 1 shows that there was also considerable variation in fee ratios across states. The table reports the two fee ratios by state for 1979,1987 , and 1992 , as well as the change over the entire period for each state. There is substantial variation both across states and within states over time. For example, on average, over this period, fee ratio A increased by 2.9 percentage points. However, fee ratio A actually fell in 20 states while it rose in 25 others; the ratio fell by over 50 percentage points in South Carolina, and rose by more than 46 percentage points in Pennsylvania.

As a check on the reasonableness of our estimates, we can compare our fee ratio for 1979 to the average fee ratio reported in a survey of ob/gyns in that year (Mitchell and Schurman, 1984), The typical ob/gyn in 1979 reported receiving $48 \%$ as much from Medicaid as from private payers for a complete obstetrical package. Our calculated fee ratios for that year are 0.55 and 0.58 , so our series are somewhat too high, perhaps because we use an index of hospital cost inflation to create

\footnotetext{
${ }^{7}$ The graph of the national average for Fee Ratio B shows the same pattern over time; the major differences between the two fee ratios are across states (within years), as shown in Table 1 .

${ }^{8}$ One reason that the rise between 1987 and 1988 is much sharper than the rise between 1988 and 1989 may be the fact that the source for 1987 (AGI, 1987), reports fees for the beginning of 1987, while the source for 1988 (ACOG, 1988) reports fees for the end of 1988 . Hence, there is effectively a two year window between these observations. Note that the data at either endpoint of the 1987 to 1988 "jump" appear reasonable, in the sense that the data before and after the jump are consistent with the values reported for 1987 and 1988 . The inclusion of year dummies in the regression will capture any average differences in the information collected from different sources. We have also tried using an interpolation of the 1986 and 1988 values of the fee ratio in place of the 1987 value from the AGI survey. The results are identical to the findings reported below.
} 
the denominator of our fee ratios.

Thus, as a further specification check, we recreated our fee index using the average regional physician fee from 1983 to 1992 as the deflator (American Medical Association, 1993). This adjustment leads to a fee ratio for 1983 which is $88 \%$ as high as the one we calculate using the hospital cost deflator. Applying this adjustment to the figures in Table 1, we estimate fee ratios for 1979 of 0.48 and 0.51 , which are very similar to the figure reported by Mitchell and Schurman. We therefore report results below for the 1983 to 1992 period using all three fee ratios.

\section{d) Medicaid Eligibility}

Our other regressor of interest is the percentage of 15 to 44 year old women who would be eligible for Medicaid coverage in the event of pregnancy in each state and year. Medicaid eligibility for pregnant women expanded dramatically over the 1980s. A detailed history of these expansions and their effects on eligibility is provided in Currie and Gruber (1994). In that paper, we used a detailed simulation model of each state's Medicaid policy, along with information from the Current Population Survey (CPS) on the characteristics of the 15 to 44 year old population, to calculate eligibility in each state/year.'

Our Medicaid eligibility measure is presented in Figure 2 and in Table 2. Until 1984, eligibility for Medicaid was closely linked to participation in the Aid to Families with Dependent

9 Actual eligibility depends not only on state Medicaid policy but also on the demographic composition of the state in that year, such as the number of low income and single women. Demographic composition may be correlated with birth outcomes for reasons independent of Medicaid policy. Hence, in order to isolate the effect of legislated eligibility changes, we constructed a "simulated" Medicaid eligibility measure by taking a national random sample of women from the CPS and calculating the fraction of these same women who would have been eligible for Medicaid in each state and year. We use this "simulated eligibility" measure below. The results using actual eligibility were very similar. See our earlier paper for a more detailed discussion of the differences between actual and "simulated" eligibility. 
Children program. Hence, Medicaid coverage of pregnancies was primarily limited to single mothers. ${ }^{10}$ Figure 2 shows that there was a small rise in eligibility in the early 1980s, followed by a drop in 1982 as AFDC generosity was reduced in the early years of the Reagan administration.

Beginning in 1984, some women who were not eligible for AFDC for reasons of family structure became eligible for Medicaid coverage of their pregnancies; childless women and women in two-parent households were the main beneficiaries of these policies. ${ }^{11}$ The result, as shown in Figure 2, was a rise in eligibility from 1984 to 1987. Then, in the late 1980s, Medicaid coverage was extended to all pregnant women with incomes above the poverty line; by 1990 , all states had to cover women up to $133 \%$ of poverty, and some states covered women up to $200 \%$ of poverty. Figure 2 shows that these broader expansions led to sharp increases in Medicaid eligibility for pregnant women towards the end of the decade.

Table 2 shows the percentage of women 15 to 44 years old who would have been eligible for Medicaid in the event of pregnancy in 1979, 1986, and 1992. The table indicates that there was a large overall rise in eligibility between 1979 and 1992 in most states. Nationally, the percentage of women eligible for Medicaid coverage of pregnancy rose from $14.2 \%$ to $34 \%$.

\section{Part III: Results}

a) Effects of Changes in the Fee Ratio

Estimates from models of the form (1) are shown in Table 3. These regressions are

${ }^{10} \mathrm{~A}$ number of additional groups received coverage in certain states as well, such as women whose incomes were above the AFDC thresholds but who had large medical expenditures (the Medically Needy); see Currie and Gruber for details.

"That is, federally mandated coverage of these groups was put into place over the 1984-87 period, although some states had already covered these groups in earlier years. 
estimated over the $1980-1992$ period for 45 states, so there are a total of 485 observations. Estimates using fee ratio A appear in the top panel, while estimates using fee ratio B appear in the bottom panel. Since estimates using the two series are very similar, we will concentrate on the estimates based on fee ratio $A$ in the discussion below.

As column (1) shows, higher fee ratios have a statistically significant negative effect on infant mortality. The point estimate implies that raising the relative Medicaid fee by 100 percentage points would lower the infant mortality rate by 0.56 deaths per 1000 births for fee ratio $A$, and by 0.51 births for fee ratio $B$. The mean infant mortality rate over this period was 10 births per 1000 , so this is a fairly small effect for a large change in fee ratios.

The remaining columns of Table 3 provide some evidence about the cost effectiveness of decreasing infant mortality by increasing fee ratios. In column (2), we regress real physician expenditures under the Medicaid program (in 100s of 1986 dollars) on the fee ratio. These estimates suggest that raising the fee ratio by 100 percentage points would raise physician expenditures under the Medicaid program by $\$ 9.60$ per 15 to 44 year old woman. The average fertility rate over this time period was 0.065 births per year for this age group which implies that the increase in physician expenditures amounts to $\$ 263,736$ per infant life saved. ${ }^{12}$ The corresponding estimate for fee ratio $\mathrm{B}$ is $\$ 289,593$.

Fee policy could have effects beyond those on physician payments, however. As a number of studies have noted, higher payments to physicians may be offset by lower payments elsewhere in the medical system. Long et al. (1985) estimate a substantial shift in the site of care from clinics

\footnotetext{
${ }^{12}$ This calculation is done as follows. For a 100 percentage point increase in the fee ratio, there is a rise in Medicaid physician expenditures of $\$ 9.60$ per 15 to 44 year old woman. Since the average fertility rate in this group is $6.5 \%$, this amounts to a cost increase of $\$ 147.70$ per birth, or $\$ 147,700$ per 1000 births. This saves 0.56 infant lives per 1000 births, for a cost per life saved of $\$ 263,756$.
} 
and hospitals to physicians' offices when fees increase. Cohen (1989) finds that higher Medicaid fees over the 1979-1984 period lowered outpatient hospital expenditures under the program. And Stuart et al. (1992) use a simulation model to show that there are substantial potential cost savings from increasing the use of physician's offices in lieu of hospital outpatient settings.

On the other hand, results from the RAND Health Insurance Experiment (Manning et al., 1987) refute the claim of substantial savings through offsets. In that study, individuals who were assigned a lower copayment rate used both more physician care and more hospital care. Similarly, if increases in the fee ratio save lives by increasing access to ob/gyns who recommend "high tech" interventions, then non-physician costs could rise. Thus, it is unclear ex ante whether physician reimbursements are a substitute or a complement for Medicaid expenditures on clinics and hospitals.

The remaining columns of Table 3 provide mixed evidence on this question. Paying higher fees to ob/gyns appears to increase expenditures on clinics, in contrast to the finding of Long et al. (1985). This may be due to the fact that higher fees are available to ob/gyns practicing in clinics, or to the difficulties involved in distinguishing between office-based and clinic-based practices in our Health Care Financing Administration data. On the other hand, the estimates in Column (3) indicate that a $100 \%$ increase in the fee ratio actually decreases expenditures on hospitals by $\$ 21.20$, although the point estimate is not statistically significant. ${ }^{13}$ The net result, expressed in the final column, is that increasing the fee ratio has an insignificant effect on total Medicaid expenditures. Thus, fee ratio increases appear to be a "free lunch" -- mortality is lowered without any attendant increase in total Medicaid expenditures. For fee ratio B, there is a smaller reduction in hospital expenditures,

${ }^{13}$ We deflate the Medicaid data on hospital expenditures using the national hospital CPI, for comparability with our physician series. We do, however, have actual statewide hospital cost inflation data from the American Hospital Association (various years) at our disposal. Using this data to deflate Medicaid hospital spending has little effect on the estimates. 
so that total expenditures do increase somewhat. Nevertheless, the implied total cost of saving an infant is quite small: $\$ 114,630$.

\section{b) Sensitivity}

One potential problem with the fee index used thus far is that the fee ratio data for the 1980 to 1982 period had to be interpolated. Hence, in Table 4, we explore the robustness of our results by focusing on the 1983 to 1992 time period. ${ }^{14}$ Table 4 indicates that our result regarding the effect of increasing the fee ratio on infant mortality is even stronger in this time period; a $100 \%$ rise in relative fees lowers mortality by 0.74 births per 1000 .

However, the results regarding expenditures are more sensitive to the choice of time interval. The effect of the fee ratio on physician costs is approximately twice as high in this time period, the effect on clinics is similar, and there is now a positive effect on hospital expenditures. The result is a net increase in total expenditures of $\$ 60.60$ per 15 to 44 year old woman. This figure suggests that the cost of saving a life through increasing fee ratios is $\$ 1,259,875$ for fee ratio $\mathbf{A}$, and $\$ 1,358,325$ for fee ratio $B$.

In the remainder of Table 4 , we explore the sensitivity of our result to the deflation methodology. As noted above, using hospital costs to proxy for private sector fee inflation led to a fee ratio which was somewhat too high in 1979 . However, the fee ratio was more accurately estimated if a regional deflator for physician fees from the AMA was used instead. The bottom two

\footnotetext{
${ }^{14}$ There are fewer than 45 states*10 years of observations, since some states do not have fee data for 1982 and 1983 also; data for these states was interpolated in the earlier table, but is not here.
} 
panels of the table therefore use this fee deflator for the 1983 to 1992 period. ${ }^{15}$ Using this deflator leads to results for both mortality and expenditures that are larger than those shown in the top panels. However, the implied cost of saving one infant life per 1000 births is quite similar: $\$ 1,317,981$ for fee ratio $\mathbf{A}$, and $\$ 1,396,234$ for fee ratio $\mathbf{B}$.

Thus, we conclude that the estimated effect of changes in the fee ratio on infant mortality is robust to the deflation methodology used and to the exclusion of the years with imputed fee data. However, our conclusions about the size of offset effects, and therefore about the cost effectiveness of fee policy, are more sensitive to the time period chosen.

\section{c) Fee Ratio and Medicaid Eligibility Results}

As discussed above, models that do not include a measure of eligibility for Medicaid could overstate the effects of changes in the fee ratio if changes in fee ratios and changes in eligibility are positively correlated, and if eligibility reduces mortality. In order to allow for this possibility, we estimate models of the form (2). The results are shown in Table 5. As in Gruber and Currie (1994), we find a sizeable and statistically significant negative effect of increased Medicaid eligibility for pregnant women on the infant mortality rate. Despite the addition of two more years of data and the deletion of some states, the estimates are almost exactly the same as those reported in our earlier paper. They imply that a 20 percentage point increase in eligibility among 15 to 44 year old women is associated with a decline in the infant mortality rate of 0.64 deaths per 1000 births. The inclusion of Medicaid eligibility reduces the estimated coefficients on the fee ratio slightly, but the effects of both fee ratios remain statistically significant at the $8 \%$ level.

\footnotetext{
${ }^{15}$ Since the fee ratio is lagged, it actually goes back to 1982 , before the AMA fee data is available. We therefore deflate the AMA data for 1983 back to 1982 using average nationwide growth in the CPI for physicians' services.
} 
Medicaid eligibility increases have a sizeable effect on Medicaid expenditures as well. Each additional eligible woman is found to increase Medicaid payments to physicians by $\$ 46.90$. This estimate implies that the increase in physician costs per infant life saved is $\$ 225,059$ under eligibility expansions. In contrast, Medicaid fee increases would cost \$275,199 in additional Medicaid expenditures on physicians per infant saved. Thus, measured in terms of their effects on physician expenditures alone, the two policies have very similar effects.

However, Medicaid eligibility expansions and fee ratio increases have quite different effects on clinic and hospital expenditures. Raising Medicaid eligibility decreases clinic expenditures, although neither of our two estimates are statistically significant. Thus, making women eligible for insurance does seem to shift their site of care from clinics to doctor's offices. At the same time, however, there is a very large increase in hospital expenditures, suggesting that Medicaid eligibility increases lead to expensive hospital interventions. Altogether, making one more woman eligible for Medicaid costs $\$ 305$ dollars, implying a total cost per life saved of $\$ 1,463,602$.

On the other hand, our point estimates imply that raising fee ratios reduces clinic and hospital expenditures, so that there is no net effect on total expenditures. In the full sample, therefore, Medicaid eligibility policy appears to be less efficient than fee policy. But it is important to note that, if we use the fee ratio results from the 1983 to 1992 sub-period, expanding eligibility and increasing fee ratios appear to be equally effective. Thus, the relative efficacy of demand and supply side policies is sensitive to the sample period chosen for the fee ratio regressions. ${ }^{16}$

${ }^{16}$ Unlike the fee data, there is no problem with the eligibility data for the 1979 to 1982 period, and this time period provides much of the interesting variation in eligibility. When we do restrict regressions including eligibility to the 1983 to 1992 period, the estimated effect of eligibility on mortality falls (with a resultant decline in the cost efficiency of the policy), although it remains significant, and it is not significantly different from the results reported for the entire period. 


\section{Part IV: Discussion and Conclusions}

This paper provides evidence that closing the gap between private fees and fees paid to doctors under the Medicaid program is an effective way to reduce infant mortality rates. Moreover, raising fee ratios may be a more cost effective way to reduce infant mortality than increasing the Medicaid eligibility of pregnant women, although our cost estimates are sensitive to the imputation of the missing fee data for the 1980-82 period.

Our estimated cost of life saving of less than $\$ 1.4$ million is at the low end of the range of recent estimates of the value of a life. Manning et al. (1989) use data from studies of willingness to pay for a small change in the probability of survival to estimate that the value of a life is $\$ 1.66$ million. ${ }^{17}$ Cropper and Oates (1992) report that studies based on compensating differentials for risk of death on the job yield a value of life of between $\$ 1.6$ and $\$ 9.0$ million; Viscusi (1992) presents a broader range, with a preferred estimate of $\$ 12.1$ million. ${ }^{18}$ These estimates suggest that the cost of saving a life through increasing fee ratios or through expanding eligibility is no greater than the amount that an adult would have been willing to pay to be kept alive.

Alternatively, we can compare the cost of saving a life through Medicaid fee ratio and eligibility policy to the cost of keeping individuals alive through other public policy interventions. Breyer (1993) reports the cost of saving a life through 53 different public policy interventions, ranging from mandatory seat belts or air bags to reduced emissions. Thirty-four of these

\footnotetext{
${ }^{17}$ This and all subsequent figures are expressed in 1986 dollars. Where deflation is necessary, it is done using the Medical care component of the CPI, for comparison to our expenditure figures. The correct deflator for this exercise is not obvious, but using different deflators would not substantially alter our conclusions.

${ }^{18}$ Furthermore, compensating wage differentials understate the amount than an average person would pay to reduce the risk of death, because the least risk-averse persons tend to take the riskiest jobs.
} 
interventions cost more than $\$ 1.4$ million per life saved, and in 5 cases, the costs per life were over $\$ 1$ billion. Cropper et al. (1992) estimate that regulations on the use of pesticides cost $\$ 60,000$ per consumer life saved, but that regulations on the production of pesticides cost $\$ 35$ million per producer life saved. Judged by this yardstick, changes in Medicaid policy appear to be a relatively efficient way of saving a life. Furthermore, if our full sample results are correct, fee policy is particularly effective relative to the alternative of expanding eligibility.

Relative to these other studies, our findings are subject to at least three biases. First, our estimates may overstate the benefits of increased Medicaid eligibility or fee ratios, because they do not take account of the fact that the infants saved may be in poor health. It is also possible that the some of same factors that decrease infant mortality also improve infant health, in which case we will underestimate the benefits associated with changes in Medicaid policy. Finally, we are valuing lives at birth, whereas the other studies are valuing the lives of workers or survey respondents. Whether this second bias is positive or negative depends in large part on whether the perspective of the infant (who is losing an entire lifetime, rather than just a set of years), or others (who are losing someone to whom they may be less attached) is considered.

There are several reasons to expect the efficacy of increased fee ratios to change over time. First, although our results suggest that fee ratios increase access to care regardless of residential segregation, it is possible that an increase in residential segregation could undermine the efficacy of this policy. Second, the effect of increased fee ratios may not be linear. We experimented with this possibility by examining the effects of $\log$ fee ratios and by including the square of the fee ratio, and found that the results were similar to those reported above. This result suggests that there are no decreasing returns to increases in fee ratios, for the range of fee ratios covered in our data. Finally, the gap between the cost of saving a life through raising fees and through increasing Medicaid 
eligibility could be reduced, if over time more women take advantage of increased eligibility in order w obtain timely prenatal care. Currie and Gruber (1994) note that recent Medicaid expansions to all women with incomes at or above the poverty line have not led to significant increases in selfreported Medicaid coverage, and therefore cannot be having much effect on the use of prenatal care - but low take-up rates may change as more people become aware of their entitlements.

Finally, we should note that there may be important population heterogeneity in the response to changing fee ratios. We have considered only the effect on the average mortality rate in the state. It would be instructive to consider the way that this effect differs by demographic characteristics and location. Are increased fee ratios lowering mortality through increased access for disadvantaged populations, perhaps operating through physician location decisions? Or is their effect largest on populations that already had some access, but whose treatment patterns improve once higher fees are being paid? Do fee policy and eligibility increases improve outcomes among different populations? And how can these policies most usefully be combined with outreach programs to identify the population of high risk births at an early date? 


\section{References}

Adams, Kathleen (1992). "Effect of Increased Medicaid Fees on Physician Participation in Tennessee, 1985-88". Mimeo, Systemetrics.

Aday, Lu Ann, and Ronald M. Anderson (1984). "The National Profile of Access to Medical Care: Where Do We Stand?," American Journal of Public Health, 74, 1331-1339.

Alan Guttmacher Institute (1987). The Financine of Maternity Care in the United States. New York: AGI.

American College of Obstetricians and Gynecologists (1988, 1990). "Medicaid Reimbursement for Obstetric Care (Specialist) by State". Washington, D.C.: ACOG.

American Hospital Association. Hospital Statistics, various years. Chicago, IL: AHA.

Breyer, Stephen (1993). Breaking the Vicious Cycle: Toward Effective Risk Regulation. Cambridge, MA: Harvard University Press.

Buehler, J.W., J. Kleinman, and C. Hogue. "Birth Weight Specific Infant Mortality, U.S., 1960 and 1980," Public Health Reports, 102 2:3564-3567, 1985.

Cohen, Joel W. (1989). "Medicaid Policy and the Substitution of Hospital Outpatient Care for Physician Care," Health Services Research, 24:33-66.

Corman, Hope, Theodore Joyce, and Michael Grossman. "Birth Outcome Production Functions in the United States," Journal of Human Resources, 22:339-360, 1987.

Cropper, Maureen, et al., "The Determinants of Pesticide Regulation: A Statistical Analy sis of EPA Decision-Making," Journal of Political Economy, 100:175-197, 1992.

Cropper, Maureen, and Wallace Oates. "Environmental Economics: A Survey," Lournal of Economic Literature, 30:675-740, June 1992.

Currie, Janet, and Jonathan Gruber. "Saving Babies: The Efficacy and Cost of Recent Expansions of Medicaid Eligibility for Pregnant Women," National Bureau of Economic Research, Working Paper \#4644, February 1994.

Decker, Sandra (1993). "The Effect of Physician Reimbursement Levels on the Primary Care of Medicaid Patients". Mimeo, New York University.

Fossett, James W., and John A. Peterson (1989). "Physician Supply and Medicaid Participation: The Causes of Market Failure," Medical Care, 27:386-396.

Fossett, James W., Janet D. Perloff, Phillip R. Kletke, and John A. Peterson (1992). "Medicaid and Access to Child Health Care in Chicago," Journal of Health Politics. Policy and Law, 
17:273-298.

Frank, Richard, Donna Storbino, David Salkever, Catherine Jackson. "Updated Estimates of the Impact of Prenatal Care on Birthweight Outcomes by Race," National Bureau of Economic Research \$3624, February 1991.

Gold, Rachel, Susheela Singh, and Jennifer Frost. "The Medicaid Eligibility Expansions for Pregnant Women: Evaluation the Strength of State Implementation Efforts," Eamily Planning Perspectives, 25 5:196-207, September/October 1993.

Gold, Rachel Benson, and Asta M. Kenney (1985). "Paying for Maternity Care," Eamily Planning Perspectives, 17, 103-111

Grossman, Michael, and Steven Jacobowitz. "Variations In Infant Mortality Rates Among Counties of the United States: The Roles of Public Policies and Programs," Demegraphy, 18, November 1981, 695-713.

Grossman, Michael, and Theodore Joyce. "Unobservables, Pregnancy Resolutions and Birth Weight Production Functions in New York City," Journal of Political Economy, 98 5:983-1007, October 1990.

Hass, Jennifer S., Seven Udarhelyi, and Arnold M. Epstein, "The Effect of Health Coverage for Uninsured Pregnant Women on Maternal Health and the Use of Cesarean Section," Lournal of the American Medical Association, 270, July 7, 1993, 61-64.

Hadley, Jack (1979). "Physician Participation in Medicaid: Evidence from California," Health Services Research, 14:266-280.

Hadley, Jack, et al. (1991). "Comparison of Uninsured and Privately Insured Hospital Patients: Condition on Admission, Resource Use, and Outcome," Journal of the American Medical Association, 265, 374-379.

Health Care Financing Administration. Analysis of State Medicaid Program Characteristics. Washington, D.C.: HCFA, 1982, 1983, 1984, 1986.

Held, Ptilip J., and John Holahan (1985). "Containing Medicaid Costs in an Era of Growing Physician Supply," Health Care Financing Review, 7(1):49-60.

Holahan, John (1982). "Paying for Physicina Services in State Medicaid Programs". Urban Institue Working Paper 2015.

Holahan, John (1991). "Medicaid Physician Fees, 1990: The Results of a New Survey". Urban Institute Working Paper 6110-01.

Horbar, Jeffrey, Elizabeth Wright, Lynn Onstad, et al. "Decreasing Mortality Associated with the Introduction of Surfactant Therapy: An Observational Study of Neonates Weighing 601 to 
1300 Grams at Birth," Pediatrics, 92 2:191-196, August 1993.

Long, Stephen H., Russell F. Settle, and Bruce C. Stuart (1986). "Reimbursement and Access to Physicians' Services Under Medicaid," Lournal of Health Economics, 5:235-251.

Manning, Williard, et al. "The Taxes of Sin: Do Smokers and Drinkers Pay their Way?," Jounnal of the American Medical Association, 261 11:1604-1609, March 17, 1989.

Mitchell, Janet B. (1991). "Physician Participation in Medicaid Revisited," Medical Care, 29:645653.

Mitchell, Janet B., and Rachel Schurman (1984). "Access to Private Obstetrics/Gynceology Services Under Medicaid," Medical Care, 22, 1026-1037.

Physician Payment Review Commission (1991). Phvsician Payment Under Medicaid. Washington, D.C.: PPRC.

Piper, J.M., et al. "Effects of Medicaid Eligibility Expansion on Prenatal Care and Pregnancy Outcomes in Tennessee," Journal of the American Medical Association, 264:2219-2223, 1990.

Rosenzweig, Mark, and T. Paul Schultz. "The Behavior of Mothers as Inputs to Child Health: The Determinants of Birth Weight, Gestation, and Rate of Fetal Growth," in Economic Aspects of Health, Victor Fuchs (ed.), University of Chicago Press: Chicago, 1982.

Rosenzweig, Mark, and T. Paul Schultz. "Estimating a Household Production Function: Heterogeneity, the Demand for Health Inputs, and their Effects on Birth Weight," Journal ef Political Economv, 91:723-746, October 1983.

Rosenzweig, Mark and T. Paul Schultz. "The Stability of Household Production Technology, A Replication," The Journal of Human Resources, 23:535-549, Fall 1988.

Saywell, Robert M. et al. "Hospital and Patient Characteristics of Uncompensated Hospital Care: Policy Implications," Lournal of Health Politics. Policy. and Law, 14:287-307, 1989.

Schwartz, Rachel. "What Price Prematurity?," Eamily Planning Perspectives, 21:170-174, 1989.

Schwartz, Anne, David C. Colby, and Anne Lenhard Reisinger (1991). "Variation in Medicaid Physician Fees," Health Affairs, Spring, 131-139.

Sloan, Frank, Janet Mitchell, and Jerry Cromwell (1978). "Physician Participation in State Medicaid Programs," Journal of Human Resources, 8:212-245.

Stuart, Mary, Donald Steinwachs, Jennifer Harlow, and Michael Fox (1990). "Ambulatory Practice Variation in Maryland: Implications for Medicaid Cost Management," Health Care Financing Review, Annual Supplement, 57-67. 
U.S. House of Representatives, Green Book 1992: Background Material on Programs Under the Jurisdiction of the Committee on Ways and Means, Washington, D.C., GPO, 1992.

U.S. Office of Technology Assessment. Neonatal Intensive Care for Low Birthweight Infants: Costs and Effectiveness, OTA-HCS-38, Washington, D.C., 1987.

Viscusi, Kip. Fatal Tradeoffs, New York: Oxford University Press, 1992.

M. Wenneker et al. (1990). "The Association of Payer with Utilization of Cardiac Procedures in Massachusetts," Journal of the American Medical Association, 264, 1255-1260. 
Table 1: Fee Ratios by State

\begin{tabular}{|c|c|c|c|c|c|c|c|c|}
\hline State & $\begin{array}{c}\text { Ratio A } \\
1979\end{array}$ & $\begin{array}{c}\text { Ratio A } \\
1986\end{array}$ & $\begin{array}{c}\text { Ratio A } \\
1992\end{array}$ & $\begin{array}{l}\text { Diff A } \\
79-92\end{array}$ & $\begin{array}{c}\text { Ratio B } \\
\text { 1979 }\end{array}$ & $\begin{array}{c}\text { Ratio B } \\
1986\end{array}$ & $\begin{array}{c}\text { Ratio B } \\
1992\end{array}$ & $\begin{array}{c}\text { Diff B } \\
79-92\end{array}$ \\
\hline AL & .48 & .44 & .59 & .11 & .51 & .43 & .77 & .26 \\
\hline $\mathbf{A R}$ & .94 & .59 & .59 & -.35 & 1.09 & .63 & .77 & -.31 \\
\hline $\mathrm{CA}$ & .35 & .30 & .37 & .02 & .48 & .40 & .46 & -.01 \\
\hline Co & .24 & .27 & .41 & .17 & .34 & .35 & .51 & .17 \\
\hline$C T$ & .22 & .20 & .35 & .14 & .23 & .22 & .34 & .11 \\
\hline DC & .18 & .19 & .35 & .17 & .23 & .35 & .52 & .29 \\
\hline DE & .79 & .51 & .57 & -.22 & 1.06 & .60 & .70 & -.36 \\
\hline FL & .32 & .27 & .51 & .18 & .29 & .22 & .43 & .14 \\
\hline GA & .44 & .56 & .74 & .29 & .45 & .58 & .68 & .23 \\
\hline HI & .65 & .38 & .38 & -.27 & 1.11 & .64 & .59 & -.52 \\
\hline IA & .67 & .90 & .80 & .14 & .56 & .73 & .61 & .06 \\
\hline ID & .73 & .59 & .94 & .21 & .76 & .58 & .90 & .14 \\
\hline IL & .44 & .42 & .56 & .12 & .43 & .39 & .58 & .05 \\
\hline IN & .97 & .90 & .79 & -.18 & .89 & .75 & .66 & -.24 \\
\hline KS & .57 & .40 & .98 & .41 & .57 & .46 & .87 & .30 \\
\hline LA & .54 & .41 & .54 & .00 & .34 & .21 & .33 & -.00 \\
\hline MA & .13 & .26 & .40 & .26 & .20 & .68 & .55 & .35 \\
\hline MD & .27 & .23 & .52 & .25 & .42 & .59 & .87 & .45 \\
\hline ME & .38 & .25 & .61 & .23 & .41 & .49 & .61 & .20 \\
\hline MI & .43 & .30 & .34 & -.09 & .53 & .36 & 39 & -.13 \\
\hline MN & .83 & .58 & .75 & -.08 & .79 & .66 & .68 & -.12 \\
\hline MO & .61 & .26 & .63 & .03 & .75 & .36 & .73 & -.02 \\
\hline MS & .50 & .55 & .56 & .07 & .50 & .53 & .56 & .05 \\
\hline MT & .68 & .61 & .57 & -.06 & .60 & .53 & .73 & .12 \\
\hline NC & .68 & .43 & .63 & -.05 & .75 & .45 & .64 & -.12 \\
\hline ND & .81 & .51 & .61 & -.20 & .38 & .23 & .33 & -.05 \\
\hline $\mathrm{NE}$ & .96 & 1.12 & .82 & -.14 & 1.14 & 1.06 & .92 & -.21 \\
\hline $\mathrm{NH}$ & .50 & .27 & .75 & .25 & .51 & .26 & .71 & .20 \\
\hline $\mathrm{NJ}$ & .20 & .13 & .15 & -.05 & .26 & .16 & .18 & -.08 \\
\hline NM & .69 & .42 & .60 & -.09 & .47 & .27 & .37 & -.11 \\
\hline NV & .93 & .62 & .95 & .02 & .78 & .59 & .84 & .07 \\
\hline NY & .11 & .22 & .25 & .15 & .15 & .28 & .33 & .18 \\
\hline $\mathrm{OH}$ & .65 & .42 & .45 & -.20 & .72 & .53 & .59 & -.12 \\
\hline OK & .84 & .91 & .61 & -.24 & .85 & .82 & .75 & -10 \\
\hline OR & .36 & .37 & .54 & .18 & .41 & .39 & .53 & .13 \\
\hline PA & .17 & .10 & .32 & .15 & .18 & .31 & .66 & .48 \\
\hline SC & 1.31 & .70 & .93 & -.38 & 1.12 & .70 & .69 & -.43 \\
\hline SD & .36 & .36 & .38 & .03 & .57 & .53 & .75 & .18 \\
\hline TN & .69 & .67 & .42 & -.27 & .86 & .78 & .71 & -.15 \\
\hline UT & .62 & .46 & .38 & -.24 & .87 & .65 & .50 & -.37 \\
\hline VA & .46 & .30 & .61 & .15 & .45 & .27 & .70 & .24 \\
\hline$V T$ & .67 & .55 & .89 & .21 & .66 & .55 & .74 & .08 \\
\hline WA & .39 & .40 & .55 & .16 & .55 & .51 & .72 & .17 \\
\hline WI & .76 & .81 & .69 & -.06 & .67 & .71 & .60 & -.07 \\
\hline WV & .37 & .22 & .65 & .28 & .54 & .30 & 1.07 & .53 \\
\hline
\end{tabular}

Notes: Each figure is the ratio of the Medicaid foe to the private fee in that state and year. Fee Ration A (Schwartz) and B (Holahan) are calculated as described in text. 
Table 2: Percent Medicaid Eligible by State

\begin{tabular}{|c|c|c|c|c|}
\hline Stute & 1979 & 1986 & 1992 & Diff $92-79$ \\
\hline AL & .11 & .12 & .31 & .20 \\
\hline$A R$ & .11 & .12 & .41 & .30 \\
\hline $\mathrm{CA}$ & .19 & .25 & .44 & .25 \\
\hline $\mathrm{CO}$ & .13 & .17 & .35 & .22 \\
\hline $\mathrm{CT}$ & .19 & .22 & .41 & .22 \\
\hline DC & .17 & .19 & .41 & .24 \\
\hline DE & .12 & .13 & .37 & .25 \\
\hline $\mathrm{FL}$ & .08 & .14 & .35 & .17 \\
\hline GA & .10 & .14 & .31 & .21 \\
\hline HI & .19 & .18 & .42 & .23 \\
\hline IA & .15 & .19 & .41 & .26 \\
\hline ID & .15 & .17 & .31 & .16 \\
\hline IL & .13 & .17 & .32 & .19 \\
\hline IN & .09 & .13 & .34 & .25 \\
\hline KS & .16 & .15 & .31 & .15 \\
\hline LA & .12 & .13 & .31 & .19 \\
\hline MA & .18 & .19 & .41 & .23 \\
\hline MD & .14 & .17 & .41 & .27 \\
\hline ME & .12 & .20 & .41 & .29 \\
\hline MI & .15 & .20 & .41 & .26 \\
\hline $\mathbf{M N}$ & .14 & .21 & .41 & .27 \\
\hline MO & .09 & .13 & .31 & .22 \\
\hline MS & .08 & .15 & .41 & .33 \\
\hline MT & .14 & .16 & .31 & .17 \\
\hline NC & .11 & .16 & .41 & .30 \\
\hline ND & .14 & .16 & .31 & .17 \\
\hline NE & .16 & .16 & .31 & .15 \\
\hline NH & .14 & .16 & .31 & .17 \\
\hline NJ & .12 & .16 & .41 & .29 \\
\hline NM & .11 & .13 & .40 & .29 \\
\hline NV & .14 & .14 & 31 & .17 \\
\hline NY & .19 & .22 & .41 & .22 \\
\hline $\mathrm{OH}$ & .13 & .17 & 32 & .19 \\
\hline OK & .13 & .17 & .31 & .18 \\
\hline OR & 18 & .18 & .31 & .13 \\
\hline PA & .14 & .19 & .31 & .17 \\
\hline SC & .11 & .16 & .41 & .30 \\
\hline SD & .14 & .15 & .31 & .27 \\
\hline TN & .11 & .12 & .41 & .30 \\
\hline UT & .18 & .25 & .31 & .13 \\
\hline VA & .13 & .28 & .31 & .18 \\
\hline VT & .23 & .27 & .44 & .21 \\
\hline WA & .16 & .25 & .32 & .16 \\
\hline WI & .15 & .23 & .36 & .21 \\
\hline wV & .13 & .15 & .35 & .22 \\
\hline
\end{tabular}

Notes: Each figure is fraction of 15-44 year old female population eligible for Medicaid in that state and year. Calculations are described in text. 


\begin{tabular}{|cccccc|}
\hline \multicolumn{7}{|c|}{ Table 3: Effects of the Medicaid Fee Ratio } \\
\hline $\begin{array}{c}\text { Dependent } \\
\text { Variable }\end{array}$ & $\begin{array}{c}\text { Infant } \\
\text { Mortality }\end{array}$ & $\begin{array}{c}\text { Physician } \\
\text { Expend. }\end{array}$ & $\begin{array}{c}\text { Clinic } \\
\text { Expend. }\end{array}$ & $\begin{array}{c}\text { Hospital } \\
\text { Expend. }\end{array}$ & $\begin{array}{c}\text { Total } \\
\text { Expend. }\end{array}$ \\
\hline Fee Ratio A (Schwartz adjusted) & & & & \\
\hline Fee Ratio & -0.556 & 0.096 & 0.106 & -0.212 & -0.010 \\
& $(0.266)$ & $(0.051)$ & $(0.057)$ & $(0.258)$ & $(0.278)$ \\
Adjusted R & 0.924 & 0.703 & 0.577 & 0.745 & 0.792 \\
$\mathrm{~N}$ & 585 & 585 & 585 & 585 & 585 \\
\hline Fee Ratio B (Holahan adjusted) & & & & \\
\hline Fee Ratio & -0.511 & 0.092 & 0.151 & -0.205 & 0.038 \\
& $(0.236)$ & $(0.045)$ & $(0.050)$ & $(0.229)$ & $(0.246)$ \\
Adjusted R & 0.924 & 0.704 & 0.582 & 0.746 & 0.792 \\
$\mathrm{~N}$ & 585 & 585 & 585 & 585 & 585 \\
\hline
\end{tabular}

Notes: All regressions include full set of state and year dummies. Standard errors in parentheses. 


\begin{tabular}{|c|c|c|c|c|c|}
\hline $\begin{array}{l}\text { Dependent } \\
\text { Variable }\end{array}$ & $\begin{array}{c}\text { Infant } \\
\text { Mortality }\end{array}$ & $\begin{array}{l}\text { Physician } \\
\text { Expend. }\end{array}$ & $\begin{array}{l}\text { Clinic } \\
\text { Expend. }\end{array}$ & $\begin{array}{l}\text { Hospital } \\
\text { Expend. }\end{array}$ & $\begin{array}{l}\text { Total } \\
\text { Expend. }\end{array}$ \\
\hline \multicolumn{6}{|c|}{ Using Hospital Cost Deflator for Private Fees } \\
\hline \multicolumn{6}{|c|}{ Fee Ratio A (Schwartz adjusted) } \\
\hline Fee Ratio & $\begin{array}{c}-0.740 \\
(0.291)\end{array}$ & $\begin{array}{c}0.157 \\
(0.054)\end{array}$ & $\begin{array}{c}0.085 \\
(0.065)\end{array}$ & $\begin{array}{r}0.364 \\
(0.261)\end{array}$ & $\begin{array}{r}0.606 \\
(0.291)\end{array}$ \\
\hline Adjusted $\mathbf{R}^{2}$ & 0.913 & 0.721 & 0.630 & 0.759 & 0.795 \\
\hline $\mathbf{N}$ & 443 & 443 & 443 & 443 & 443 \\
\hline \multicolumn{6}{|c|}{ Fee Ratio B (Holahan adjusted) } \\
\hline Fee Ratio & $\begin{array}{c}-0.632 \\
(0.261)\end{array}$ & $\begin{array}{c}0.130 \\
(0.049)\end{array}$ & $\begin{array}{c}0.142 \\
(0.058)\end{array}$ & $\begin{array}{r}0.286 \\
(0.233)\end{array}$ & $\begin{array}{c}0.558 \\
(0.260)\end{array}$ \\
\hline Adjusted $\mathbf{R}^{2}$ & 0.913 & 0.720 & 0.634 & 0.756 & 0.795 \\
\hline $\mathbf{N}$ & 443 & 443 & 443 & 443 & 443 \\
\hline \multicolumn{6}{|c|}{ Using AMA Regional Fee Index Deflator for Private Fees } \\
\hline \multicolumn{6}{|c|}{ Fee Ratio A (Schwartz adjusted) } \\
\hline Fee Ratio & $\begin{array}{c}-0.942 \\
(0.317)\end{array}$ & $\begin{array}{c}0.188 \\
(0.059)\end{array}$ & $\begin{array}{c}0.090 \\
(0.071)\end{array}$ & $\begin{array}{r}0.529 \\
(0.284)\end{array}$ & $\begin{array}{r}0.807 \\
(0.317)\end{array}$ \\
\hline Adjusted $\mathbf{R}^{2}$ & 0.914 & 0.722 & 0.630 & 0.760 & 0.796 \\
\hline $\mathbf{N}$ & 443 & 443 & 443 & 443 & 443 \\
\hline \multicolumn{6}{|c|}{ Fee Ratio B (Holahan adjusted) } \\
\hline Fee Ratio & $\begin{array}{c}-0.768 \\
(0.283)\end{array}$ & $\begin{array}{c}0.155 \\
(0.053)\end{array}$ & $\begin{array}{c}0.171 \\
(0.063)\end{array}$ & $\begin{array}{c}0.371 \\
(0.254)\end{array}$ & $\begin{array}{c}0.697 \\
(0.282)\end{array}$ \\
\hline Adjusted $R^{2}$ & 0.913 & 0.721 & 0.635 & 0.759 & 0.796 \\
\hline $\mathbf{N}$ & 443 & 443 & 443 & 443 & 443 \\
\hline
\end{tabular}

Notes: All regressions include a full set of state and year dummies. Standard errors in parentheses. Top two panels use the basic fee ratios; bottom two panels deflate the private fee with an AMA regional physician fee index, rather than with AHA hospital costs. 


\begin{tabular}{|c|c|c|c|c|c|}
\hline $\begin{array}{l}\text { Dependent } \\
\text { Variable }\end{array}$ & $\begin{array}{c}\text { Infant } \\
\text { Mortality }\end{array}$ & $\begin{array}{l}\text { Physician } \\
\text { Expend. }\end{array}$ & $\begin{array}{c}\text { Clinic } \\
\text { Expend. }\end{array}$ & $\begin{array}{l}\text { Hospital } \\
\text { Expend. }\end{array}$ & $\begin{array}{l}\text { Total } \\
\text { Expend. }\end{array}$ \\
\hline \multicolumn{6}{|c|}{ Fee Ratio A (Schwartz adjusted) } \\
\hline Fee Ratio & $\begin{array}{l}-0.464 \\
(0.265)\end{array}$ & $\begin{array}{c}0.083 \\
(0.051)\end{array}$ & $\begin{array}{c}0.112 \\
(0.057)\end{array}$ & $\begin{array}{l}-0.292 \\
(0.258)\end{array}$ & $\begin{array}{l}-0.098 \\
(0.277)\end{array}$ \\
\hline $\begin{array}{c}\text { Eligibility } \\
\text { (\% of } 15-44 \text { women) }\end{array}$ & $\begin{array}{l}-3.206 \\
(0.999)\end{array}$ & $\begin{array}{c}0.469 \\
(0.192)\end{array}$ & $\begin{array}{l}-0.185 \\
(0.214)\end{array}$ & $\begin{array}{l}2.777 \\
(0.973)\end{array}$ & $\begin{array}{c}3.050 \\
(1.045)\end{array}$ \\
\hline Adjusted $\mathbf{R}^{2}$ & 0.926 & 0.706 & 0.577 & 0.749 & 0.795 \\
\hline $\mathbf{N}$ & 585 & 585 & 585 & 585 & 585 \\
\hline \multicolumn{6}{|c|}{ Fee Ratio B (Holahan adjusted) } \\
\hline Fee Ratio & $\begin{array}{r}-0.420 \\
(0.236)\end{array}$ & $\begin{array}{c}0.079 \\
(0.045)\end{array}$ & $\begin{array}{c}0.157 \\
(0.050)\end{array}$ & $\begin{array}{l}-0.285 \\
(0.229)\end{array}$ & $\begin{array}{l}-0.049 \\
(0.246)\end{array}$ \\
\hline Eligibility & $\begin{array}{c}-3.179 \\
(1.001)\end{array}$ & $\begin{array}{c}0.462 \\
(0.192)\end{array}$ & $\begin{array}{c}-0.221 \\
(0.213)\end{array}$ & $\begin{array}{c}2.794 \\
(0.974)\end{array}$ & $\begin{array}{c}3.035 \\
(1.047)\end{array}$ \\
\hline Adjusted $\mathbf{R}^{2}$ & 0.926 & 0.706 & 0.582 & 0.749 & 0.795 \\
\hline $\mathbf{N}$ & 585 & 585 & 585 & 585 & 585 \\
\hline
\end{tabular}

Notes: All regressions include a full set of state and year dummies. Standard errors in parentheses. 


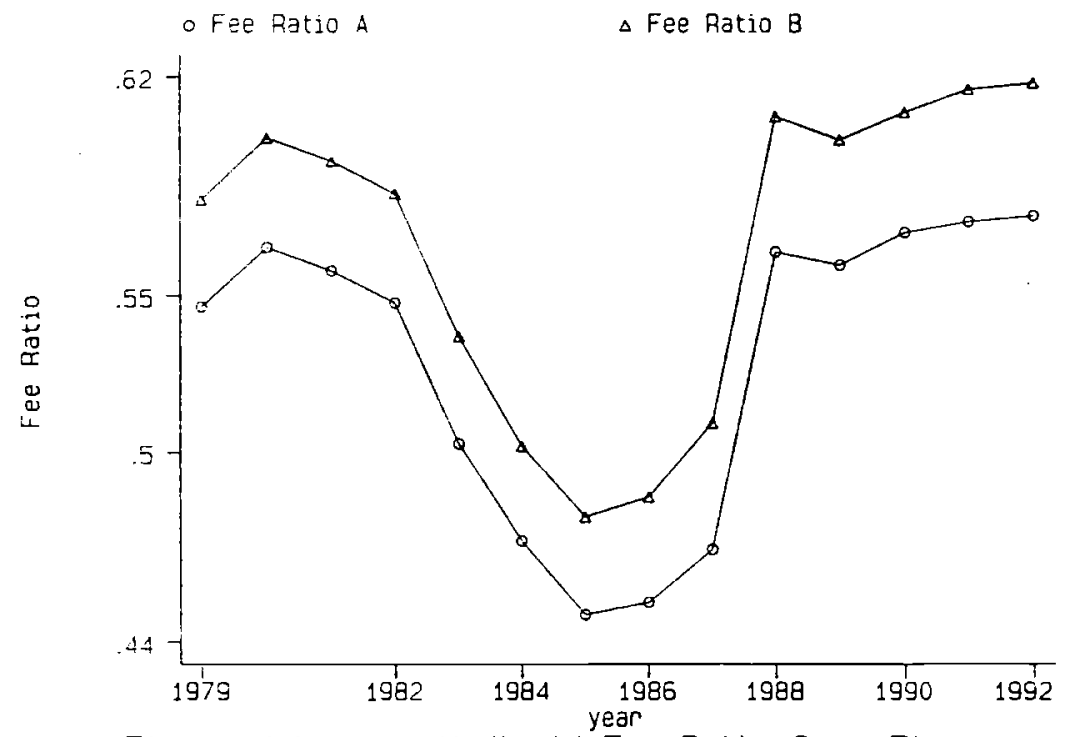

Figure 1:Average Medicaid Fee Ratio Over Time 


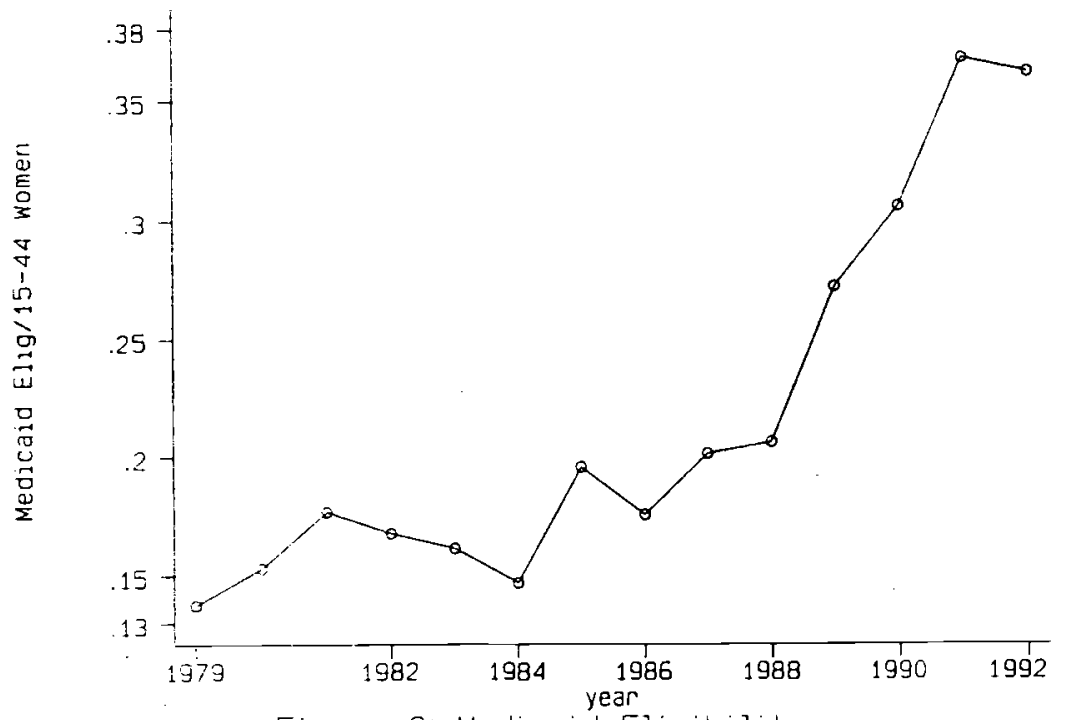

Figure 2: Medicaid Eligibility 